\title{
Urbanização e mobilidade em Curitiba: gênese, desenvolvimento e reflexões
}

Zeno Crocetti ${ }^{*}$

\section{Resumo}

A cidade de Curitiba é conhecida internacionalmente pelo eficiente e inovador sistema de transporte coletivo. Como todas as ideias novas, o sistema que possibilitou a integração urbana de Curitiba foi cercado de dúvidas. Não foi incentivada a integração independente dos municípios da Região Metropolita, favorecendo a dependência da capital. Alternativa seria o subsídio ou tarifas por anel, que também promoveriam o desenvolvimento e independência dos municípios. O custo do transporte ou de informatização/automação é muito elevado, o que dificulta parcerias com a iniciativa privada para investimentos.

Palavras chave: Metropolização; Urbanização; Geografia urbana e mobilidade.

Urbanization and mobility in Curitiba: genesis, development and reflections

\section{Abstract}

The city of Curitiba is internationally known for efficient and innovative system of collective transport. As all the new ideas, the system that allowed the urban integration of Curitiba was surrounded by doubts. There was encouraged the integration of independent municipalities in the Metropolitan Region, favoring the dependence of capital. An alternative would be the allowance

\footnotetext{
Professor da UNILA.
}

Geosul, Florianópolis, v. 29, ESPECIAL, p 93-116, jul./dez. 2014 
CROCETI, Z. Urbanização e mobilidade em Curitiba: gênese, ...

or rates per ring, which also promote the development and independence of municipalities. The cost of transport or computerisation/automation is very high, which makes partnerships with the private sector for investment.

Key words: Metropolization; Urbanization; Urban geography and mobility.

\section{Introdução}

A formação e estruturação do sistema urbano da Região Sul configura uma rede de centros bem distribuídos no território, porém com nítidas áreas de concentração. A trajetória da organização desse sistema resulta da ocupação econômica da Região e se consolida com a reestruturação de sua base produtiva. Os anos 1970 constituem o marco dessa reestruturação, com as mudanças ocorridas no setor agropecuário gerando o esvaziamento de extensas áreas rurais e o direcionamento dos fluxos migratórios para diversos centros urbanos. Num processo seletivo, alguns desses centros se consolidaram em áreas de elevada densidade, outros não tiveram sustentação econômica para manter o acréscimo populacional.

Nesse período a base produtiva da Região apresenta progressiva diversificação, inclusive na agropecuária, pela modernização da produção e pela grande expansão de culturas, que permite a entrada na comercialização de commodities e da agroindústria. No setor industrial, surgem ramos modernos na linha da metalomecânica.

Essa diversificação da base produtiva da Região Sul altera o perfil da economia dos estados. No Paraná, as atividades do setor primário, que em 1970 respondiam por mais de $40 \%$ da renda gerada, progressivamente passam a ser superadas pelas do setor secundário, que consolida sua participação atingindo, em 1996, quase $50 \%$ dessa renda. Mesmo assim, a agricultura continua a ter um papel relevante, dada a dinâmica multiplicadora em toda a 
CROCETI, Z. Urbanização e mobilidade em Curitiba: gênese, ...

cadeia produtiva, uma vez que $65 \%$ do valor bruto da produção agropecuária corresponde à produção de soja, trigo e milho importantes como commodities e base do segmento agroindustrial de primeiro processamento, bem como enquanto insumos à cadeia proteico-animal.

Todas essas transformações impactaram fortemente Curitiba e Região Metropolitana, causando um esgarçamento e deterioração dos serviços públicos de modo geral, nós iremos mostrar um pouco dos problemas de mobilidade causado por esse crescimento desordenado e o esforço do poder público de intervir para solucionar essas questões.

\section{Gênese do planejamento}

Nesse trabalho optei por analisar a abrangência da Região Metropolitana de Curitiba, porque houve várias alterações nos últimos 10 anos e hoje a região metropolitana de Curitiba ficou tão extensa que faz divisa com o estado de Santa Catarina e São Paulo. E a chamada região estendida tem hoje 29 municípios. Dentro dessa abrangência territorial que é pensado o problema do transporte urbano de Curitiba. Embora a Integração atual só cubra 14 municípios, deixando de fora outros 15.

Curitiba teve a sorte de nos anos 1940 ter um articulador e planejador nato, o engenheiro Ivo Arzua, que depois foi eleito prefeito, ele que foi o principal mentor e fundador do Instituto de Pesquisa e Planejamento Urbano de Curitiba (IPPUC). Ele estudou e passou uma temporada na Europa e trouxe essa ideia do planejamento urbano de lá, uma vez que desde o final do século XIX Curitiba já se encontra totalmente orientada para uma europeização. Ele trouxe um grupo de franceses para fazer um estudo de planejamento e viabilidade viária em Curitiba, que na época ainda era uma capital provinciana, com aproximadamente 180 mil habitantes. Então eu fico imaginando já o gestor público tendo uma ideia de futuro. Talvez por conta dessa herança que em Curitiba se desenvolveu os planos mais complexos, mais atuais, 
CROCETI, Z. Urbanização e mobilidade em Curitiba: gênese, ...

eles estão disponíveis para pesquisa e estudos na rede no portal do IPPUC (CAMPOS 2005).

Segundo MENEZES (1996), como capital da província, Curitiba deveria possuir um perfil de cidade organizada. Já 1855 o francês Pierre Taulois estabeleceu novo traçado para a cidade com ruas em linha reta e cruzamentos em ângulos retos. Considerado avançado para a época, esse plano já preparava a área central da cidade para tráfego com maior fluidez. Nesse período teve início uma estratégia para apagar a influência portuguesa mouresca da arquitetura e traçado da Cidade de Curitiba, além da ideia do branqueamento da população e da negação da escravidão negra, tendo inclusive historiadores paranaenses de renome embarcado nessa farsa, ocultando o projeto racista da Colônia Açungui, de remoção, purificação e purgação dos portugueses e negros do Paraná.

Iniciou-se então a atração de imigrantes europeus, visando a formação de colónias agrícolas ao redor da cidade. Chegaram imigrantes alemães, italianos, poloneses, ucranianos, russos, franceses, austríacos, holandeses e suíços, entre outros, consolidando núcleos que, posteriormente, se transfonaram nos bairros do Pilarzinho, Ahú, Mercês, Bacacherl, Abranches, Santa Cândida, Orleans e Santa Felicidade (IPPUC, 2001). Calcula-se que entre 1872 e 1900, vieram para Curitiba cerca de $30 \mathrm{mil}$, em 1872 Curitiba possuía uma população de 12.651 , que passou para 49.755 em 1900 e para 78.986 habitantes em 1920 (IBGE).

Kuchpil (2002) afirma que, devido a esse rápido crescimento da população, em 1895 foi instituído o primeiro Código de Posturas de Curitiba, que estabelecia normas para o ordenamento e crescimento da cidade, sobretudo no aspecto da higienização, como por exemplo, o recuo mínimo entre as casas. Menezes (1996) destaca que "ideias grandiloquentes de modernização, higienização e funcionalidade passaram a fazer parte do discurso e das ações dos prefeitos que se seguiram. A meta era a criação de uma cidade identificada funcional e esteticamente aos moldes europeus. Paris, 
CROCETI, Z. Urbanização e mobilidade em Curitiba: gênese, ...

das grandes reformas do prefeito Haussmanm era o exemplo a ser seguido.

Com a estrada de ferro Curitiba-Paranaguá, inaugurada em 1885, levou à construção da Estação Ferroviária - a nova porta de entrada da cidade - no prolongamento da rua da Liberdade (atual Barão do Rio Branco), no sentido Sul da cidade. A seguir, nas décadas de 20 e 30 foram abertas três grandes avenidas, com 30 metros de largura: a Av. Visconde de Guarapuava, a Av. Sete de Setembro e a Av. Silva Jardim, que iniciavam na Estação Ferroviária e seguiam para o Oeste da cidade, em direção ao bairro do Batel (KUCHPIL, 2002).

De acordo com Menezes (1996) a cidade teve um crescimento considerável até o começo da década de 1940, quando já contava com uma população de 140.656 habitantes quase o dobro dos 78.986 habitantes de 1920 (CAMPOS 2005). Com esse crescimento vieram as primeiras preocupações com os problemas urbanos, tomando-se necessário um planejamento que desse à cidade uma fisionomia própria. Deste modo, foi encomendado o primeiro Plano de Urbanização de Curitiba, conhecido como Plano Agache (IPPUC, 1979)

\section{O Plano Agache}

Conforme Menezes (1996), o Plano Agache, de 1943, realizado pela empresa paulista Coimbra Bueno \& Cia Ltda., com a supervisão técnica do urbanista francês Donat Alfred Agache, destaca-se pelo seu caráter organicista. A cidade é comparada a um organismo vivo, cujo tratamento dos problemas é feito através do zoneamento funcional e de intervenções diretas sobre determinados setores. Santoro (2002) destaca que esse zoneamento funcional seria alcançado através da implantação dos seguintes centros funcionais setorizados: Comercial (Centro), Administrativo (Centro Cívico), Militar (Bacacheri), Esportivo (Tarumã), Abastecimento (Mercado Municipal), Educação (Centro Politécnico), Industrial (Rebouças) e de Lazer (Parques), como mostrado no Mapa 1. 
CROCETI, Z. Urbanização e mobilidade em Curitiba: gênese, ...

\section{Mapa 1 - Plano Agache}




CROCETI, Z. Urbanização e mobilidade em Curitiba: gênese, ...

Para descongestionar o trânsito, seria feita uma remodelação no sistema viário com a adoção de quatro vias perimetrais, cofiadas por vias diametrais, além de várias vias radiais. Através da canalização dos principais nós e obras de saneamento básico, seria garantida a prevenção de surtos epidémicos e a eliminação de enchentes Nienezes (1996).

Segundo Oliveira (2001), embora as propostas do Plano Agache não tenham sido implantadas em sua totalidade algumas intervenções perduraram na Cidade como o Centro Cívico, o Campus da UFPR, no bairro Jardim das Américas, o centro militar no Bacacheri e algumas galerias de águas pluviais na rua XV de Novembro, entre outras. (CAMPOS 2005).

\section{O Plano Serete}

A população de Curitiba aumentou de 140 mil habitantes, em 1940, para cerca de 361 mil, em 1960. Quando o Departamento de Urbanismo da Prefeitura Municipal de Curitiba pretendia solicitar propostas para uma revisão do Plano Agache, a Companhia de Desenvolvimento Económico do Paraná (CODEPAR) se propôs a custear um novo plano para Curitiba (OLIVEIRA, 2001). O Plano Preliminar de Urbanismo, também conhecido como Plano Serete foi o plano vencedor da concorrência administrativa lançada em outubro de 1964 pelo Departamento de Urbanismo. O estudo foi desenvolvido pela empresa paulista Sociedade Serete de Estudos e Projetos Ltda., em colaboração com o escritório de Jorge WilheimArquitetos Associados (SERETE, 1965).

O Mapa 2 mostra as diretrizes do Plano Preliminar, onde se percebe a proposta de expansão do centro através das Zonas Comerciais, bem como de adensamento na região Sudoeste, junto à Zona Industrial proposta ao longo da rodovia BR-116.

Para auxiliar a equipe de São Paulo, foi formada a Assessoria de Pesquisa e Planejamento Urbano de Curitiba (APPUC), composta por alguns arquitetos e urbanistas recémformados pela UFPR. A APPUC originou, em 1965, o Instituto de 
CROCETI, Z. Urbanização e mobilidade em Curitiba: gênese, ...

Pesquisa e Planejamento Urbano de Curitiba (IPPUC), criado para ser o responsável pela implantação e controle do Plano Diretor elaborando e detalhando diferentes projetos e soluções em zoneamento, loteamento e renovação urbana TREMARIN (2001).

MAPA 2 Plano Preliminar de Urbanismo - 1965 - zoneamento



Fonte: IPPUC. 2001 
CROCETI, Z. Urbanização e mobilidade em Curitiba: gênese, ...

Seguindo as diretrizes propostas pelo Plano Preliminar, em 31 de Julho de 1966, durante a gestão do prefeito Ivo Arzua, foi sancionada a Lei do Plano Diretor de Curitiba, visando "propiciar melhores condições para o desenvolvimento integrado e harmónico e o bem-estar social da comunidade bem como da região metropolitana de Curitiba" (PMC, 1966).

Baseado no tripé - sistema viário, uso do solo e transporte de massa - o plano tinha as seguintes diretrizes (IPPUC, 1979):

- O uso e ocupação diferenciada do solo;

- A mudança do sentido radial de expansão para uma configuração linear, a partir de eixos estruturais, integrando sistema de transportes e uso do solo;

- A hierarquização do sistema viário;

- O descongestionamento da área central e a preservação do Centro;

- A pedestrização do Centro;

- A criação de uma paisagem urbana típica de Curitiba;

- A contenção da população metropolitana dentro dos limites físico-territoriais da cidade, evitando-se a conurbação com Curitiba, a partir da organização dos municípios da Região Metropolitana de Curitiba (RMC) em um sistema estruturado de cidades;

- A industrialização em áreas reservadas, fortalecendo a economia;

- O atendimento dos bairros em educação, saúde, circulação, áreas verdes, recreação e lazer, equipando a cidade em geral. (CAMPOS 2005).

Segundo Pereira (1993), o sistema viário seria organizado com base em uma hierarquia de vias, contendo as seguintes categorias: avenidas de acesso, vias rápidas estruturais, vias coletoras avenidas de ligação entre bairros, mas, avenidas e praças, galerias e alamedas para a circulação de pedestres. A este sistema viário deveria ser atrelado um uso do solo condizente com seu papel de indutor do crescimento da cidade Segundo SOUZA (1999), as "avenidas seriam margeadas por torres isoladas 
CROCETI, Z. Urbanização e mobilidade em Curitiba: gênese, ...

formando monumentos esculturais e se apresentaram mescladas com residências individuais propiciando, dentro dos padrões do urbanismo modernista, uma adequada densidade e salubridade" (CAMPOS 2005).

Deste modo, o adensamento populacional seria feito ao longo das vias estruturais, que deveriam conter os edifícios de maior altura - denominados de torres residenciais - garantindo o propósito de crescimento linear do centro da cidade (OLIVEIRA, 2000). Conforme (2001), esta verticalização ao longo das vias estruturais alcançaria o objetivo de gerar uma "paisagem urbana típica", uma vez que cada quadra deverá ter apenas três edifícios, cercados por áreas verdes definidas por parques, Jardins e áreas para o lazer.

Completando o tripé, o plano previa a organização do transporte coletivo ao longo dos eixos de adensamento. Segundo Oliveira (2000), tanto no detalhamento do sistema viário, quanto na definição do zoneamento, o transporte coletivo deverá ser enfatizado, em detrimento do transporte individual. Esta ênfase seria dada através da criação de vias exclusivas para o tráfego de ônibus ao longo dos eixos estruturais, assegurando rapidez e conforto a seus usuários.

\section{O período do City marketing}

Segundo Oliveira (2000) e Tremarin (2001), em sua terceira gestão, 1988-1992, Jaime Lerner optou por uma mudança de enfoque substancial, enfatizando realizações de grande impacto visual: Rua 24 Horas, Teatro Opera de Arame, Jardim Botânico, Universidade Livre do Meio Ambiente, Secretaria do Meio Ambiente e as Estações Tubo para o sistema de ônibus Linha Direta ("ligeirinhos"), atualizando o mito de vanguarda urbanística do início da década de 1970.

De acordo com García (1997), se nos anos 1970 a cidade de Curitiba podia ter sua imagem sintetizada através dos termos "cidade funcional", "cidade humana" e "cidade laboratório" nos 
CROCETI, Z. Urbanização e mobilidade em Curitiba: gênese, ...

anos 90 seus administradores constroem novas sínteses, atualizando a imagem de Curitiba como "capital ecológica", "cidade modelo' "cidade com melhor qualidade de vida do país" e "capital brasileira de Primeiro Mundo.

Com o City marketing, essa imagem de cidade preocupada com a qualidade de vida e a preservação do meio ambiente rendeu à Curitiba, e em especial a seu administrador um grande prestígio, tanto nacional quanto internacional. Porém, qualidade de vida não era exatamente o que se encontrava no modelo de adensamento dos Setores Estruturais. Souza (1999) destaca que paredes contínuas de edificações, justapostas lado a lado, com pequenas distâncias entre si ou coladas pelas divisas laterais, foram sendo formadas ao longo das vias estruturais.

Após uma década de ocupação, começaram a surgir os primeiros estudos do impacto causado por esse modelo de adensamento. Lobo, Scheer e Campos (1988) alertavam, através da visualização da morfologia urbana futura de uma região do bairro do Portão - localizado na via estrutural Sul - que, caso fossem mantidos os potenciais construtivos para o Setor Estrutural haveria o comprometimento futuro da área em termos de insolação, ventilação, circulação, escala e paisagem (CAMPOS 2005). RABINOVITCH (1996) afirma que, em um período de 20 anos, a ocupação nos Setores Estruturais passou de 6 famílias por ha em 1970, para 52 famílias por ha em 1990, correspondendo a um crescimento de $822 \%$.

Em 1990, foi feita uma revisão dos parâmetros construtivos para o Setor Estrutural através do Decreto no 579, onde se reconhecia que "os parâmetros em vigor resultam em uma densidade de ocupação excessivamente alta, ocasionando a deterioração da qualidade ambiental urbana desse setor, em especial quanto à aeração e insolação das edificações" (PMC, 1990). Conforme Oliveira (2000), o Decreto $n^{\circ}$ 579/90, buscava restringir e reordenar a forma como se configurava a ocupação do solo no Setor Estrutural. Entre as alterações, estava a redução do 
CROCETI, Z. Urbanização e mobilidade em Curitiba: gênese, ...

coeficiente de aproveitamento para quatro vezes a área do terreno, tanto na via central, como nas vias externas e nas demais vias.

Essa perda de área a ser edificada poderia ser recuperada pelos Incorporadores, através da compra de potencial construtivo, a ser utilizado em empreendimentos na ZR-4 ou em outras zonas de menor densidade. Em 1991 foi instituída a Concessão de Incentivo Construtivo, através da Lei $\mathrm{n}^{\mathrm{o}} 7.841$, conhecida como Lei do Solo Criado, que seria regulamentada posteriormente, pelo Decreto $\mathrm{n}^{\mathrm{o}}$ 86/92 (PMC, 1991, 1992). Essa lei possibilitava, para algumas áreas da cidade onde se desejava incentivar a ocupação, um aumento de $15 \%$ no potencial de aproveitamento do terreno e a adição de dois pavimentos na altura máxima dos edifícios. Para tanto, os construtores poderiam adquirir este potencial construtivo, pagando ao município $70 \%$ do valor adicional obtido no preço do imóvel. Esses recursos seriam utilizados pelo município para financiar a habitação de interesse social (OLIVEIRA 2000).

$\mathrm{Na}$ gestão do prefeito Rafael Greca, no período de 19931996, houve a continuidade da política ecológica e das grandes obras, onde se destacam os Faróis do Saber, utilizados como bibliotecas de bairro e as Ruas da Cidadania, que descentralizavam vários serviços administrativos, concentrando-os através destes equipamentos, implantados nos centros mais desenvolvidos de determinados bairros, junto aos terminais de transporte coletivo.

\section{O novo milênio 2001 A 2014}

Devido as sucessivas críticas contra o grupo político que administra Curitiba desde de 1989, a gestão e planejamento passa priorizar a construção de uma cidade mais humana em que a estruturação urbana do território garanta um desenvolvimento Sustentável e Integrado e onde os projetos e ações da Prefeitura de Curitiba sejam solidários com toda a metrópole. Os serviços sociais - saúde, educação, creches - são estruturados em redes. São criados o Linhão do Emprego que cria opções de emprego e renda em 15 bairros periféricos. Boa parte de toda essas intervenções e 
CROCETI, Z. Urbanização e mobilidade em Curitiba: gênese, ...

planejamentos foram feitos pelo IPPUC, e executados e gerenciados pela Urbanização de Curitiba (URBS) cuja principais atribuições são:

Planejamento e gerenciamento dos serviços de transporte Administração, manutenção e comercialização do uso de equipamentos urbanos e espaços públicos:

- Transporte coletivo Urbano e metropolitano;

Transporte escolar

Transporte comercial

Táxi sinalização);

- Sistema viário (Terminais, pontos, manutenção e

Estacionamento em vias públicas regulamentado (estar ou zona azul)

Fiscalização (Semtran, agentes de trânsito)

- Engenharia de trânsito (equipamentos, radares, lombadas eletrônicas, etc.);

- Planos Comunitários;

- Rodoferroviária;

- Terminais de Transporte;

- Ruas da Cidadania;

- Shopping Popular;

- Publicidade nos Equipamentos Urbanos.

O planejamento urbano continua integrando todas as políticas setoriais através de intervenções urbanísticas que mudam cenários socioculturais e econômico-produtivos. A participação popular é a maior virtude deste período ao permitir priorizar o que a população realmente precisa, acrescentando o conceito de equidade a uma gestão cada vez mais compartilhada e democrática, essa aproximação é feita através de consultas populares para a efetivação do orçamento. Nesse período e efetivado várias ampliações e integração do transporte público, criando linhas diretas do sistema ligeirinho com os municípios da RMC. 
CROCETI, Z. Urbanização e mobilidade em Curitiba: gênese, ...

\section{$O$ transporte de massa e mobilidade urbana}

Desde sua origem foi exigido do município que tivesse que se cuidar do planejamento e não misturar as áreas. Então foi feito um desenho na área central para se expandir em direção aos bairros, com uma delimitação da área industrial mais ao Sul. Que foi onde iniciou a industrialização de Curitiba, com as fábricas de mate, com os moinhos de trigo, as torrefações de café, fábrica de bebidas, caracterizando uma zona industrial.

Por isso que a área Norte ficou com um ar mais residencial, ela está muito mais preservada, do ponto de vista do urbanismo e também devido ao relevo já que ao norte é mais dobrado com a presença de muitos morros. Você tem nessa região a maioria, se quase todos os parques públicos do município, muito jardins e centenas de condomínios fechados. Na parte Sul uma planície aluvial da Bacia do Rio Belém, junto da antiga área industrial e no extremo Sul tínhamos pequenas e grandes fazendas onde era desenvolvida a pecuária e agricultura, até hoje de certa maneira, preserva uma característica mais rural, com pequenas chácaras remanescentes desse período.

Essas regiões mais distantes do centro, mais tarde tornaramse bairros residenciais mais povoados e populares, principalmente onde se localizava a bacia leiteira de Curitiba que era tocada pelos Alemães Menonitas e que fizeram a primeira usina de processamento. Chegaram ao auge nos anos 1950, concentrado $70 \%$ da do abastecimento da capital, mais tarde se transferiram para o $2^{\circ}$ planalto, em Palmeira onde se fundiram com os alemães vindos de Santa Catarina criando a colônia Witmarsum.

Essa região das grandes fazendas foi a última área de grandes loteamentos, Pinheirinho, Boqueirão, Umbará, Sitio Cercado e Campo do Santana com os loteamentos e conjuntos habitacionais do BNH e depois da COHAB. Agora o Minha Casa Minha Vida foi mais direcionado para a região metropolitana, pois não há mais estoque de terras apropriada para grandes conjuntos habitacionais. Foi justamente esse adensamento populacional que 
CROCETI, Z. Urbanização e mobilidade em Curitiba: gênese, ...

pressionou os administradores públicos de Curitiba a desenvolver um eficiente transporte público de massa que atendesse essa grande demanda.

Então, temos duas Cidades, eu acho que fica claro que ao Norte está mais fragmentado por ser uma área desde do início mais residencial e no Sul por ser área rural a coisa ficou mais latifundiária, então os bairros são imensos e sua fragmentação proporcionou áreas industriais, comerciais e formação de centenas de conjuntos habitacionais. A partir dos anos 1940 foi o primeiro esboço de planejamento como vimos, foram feitas avenidas principais para o transporte coletivo, que é implantado nos anos 1950 e nos anos 1960 se torna definitivo com canaletas exclusivas para ônibus. Com a administração do Jaime Lerner nos anos 1970 que era um arquiteto e professor universitário e herdou todo esse planejamento prévio. Também foi beneficiado pelo $2^{\circ}$ PND do governo Geisel, com investimentos em infraestruturas e descentralização industrial. Em seu governo (1975) foi implantada a Cidade Industrial de Curitiba (CIC)

\section{A estrutura e operacionalização do transporte em Curitiba e na RMC}

Provavelmente por problemas políticos esses planos só ganharam força nos anos 1970, Lerner era filiado na Arena depois PDS, legenda da sustentação da ditadura. Em 1960 Curitiba tinha 300 mil habitantes já em 1970 Curitiba chega a 600 mil habitantes, por conta das demandas vindas do interior e modernização do campo. Podemos imaginar o impacto populacional em Curitiba em apenas 10 anos. Nessa época começa o favelamento, que é uma situação crítica para o urbanismo. A necessidade de uma solução de transporte de massa era urgente.

Hoje o Município de Curitiba e RMC estão de certa forma mais integrados, as regiões mais periféricas passaram a ser integradas. Os terminais de ônibus foram espalhados, mais ou menos nesse formato de círculo e é claro que as regiões que estão 
CROCETI, Z. Urbanização e mobilidade em Curitiba: gênese, ...

mais densamente ocupadas que é a parte Sul, foram mais integrados e tiveram as maiores demandas. Em função disso existem mais terminais no Sul. O sistema viário com canaleta exclusiva, foi implantado por Lerner, quando foi indicado para prefeito em 1970 - 1972, ele começa esse tipo de planejamento de transporte coletivo. As canaletas que chamamos de expressa é inaugurada é 1975, que faz primeiro essa ligação norte sul e depois leste oeste.

Atualmente temos nos principais eixos de transportes e os principais tipos de vias. O sistema de linha direta (ligeirinho) onde o embarque é feito em Estações Tubos onde o passageiro faz o acesso por plataformas, para se fazer o embarque no mesmo nível do ônibus já com a tarifa paga, para acelerar o embarque.

Todos os ônibus expressos convencionais foram substituídos por modernos tri-articulados de cor azul, os mais modernos, em vias com canaletas exclusivas, o chamado ligeirões. No chamado anel central, existe o Circular Centro que faz integração eixos norte sul e leste oeste, e mais afastados o sistema de Interbairros que interliga todo o sistema.

A chamada linha direta (ligeirinho), os interbairros para integração e nos bairros de menor fluxo os ônibus alimentadores a partir dos terminais secundários. Existe o sistema convencional, bairro centro em vias de transito compartilhado, os ônibus amarelos. Que são automatizados (catraca eletrônica) o sujeito aceso o sistema com o cartão transporte os ônibus não dispõem de cobrador. E a linha turismo com o duplo-deck.

1.945 é a frota operante no sistema RIT, com passageiros transportados por dia útil em média de 2.270.000. Agora passageiros pagantes é 1.030 .000 , apenas 1 milhão pagando passagem! Mas é preciso considerar a integração, um mesmo passageiro pode ser contado três vezes e as categorias que não pagam passagem, como idosos, estudantes, então se não fosse subsidiada a tarifa a coisa seria bem mais cara. Hoje (2014) está em $\mathrm{R} \$ 2,70$. O transporte coletivo de massa começa mesmo em 1975, ele chega saturado em 1982, quando começa a ser planejado 
CROCETI, Z. Urbanização e mobilidade em Curitiba: gênese, ...

a integração, que vai entrar as integrações de linhas longas, circular. Os ônibus não entram no troncal do centro, apenas percorre, se o sujeito quiser ir ao centro vai ter que parar no terminal de integração. No final dos anos 1980, o volume de pessoas transportadas era bem superior ao volume do hoje. Com a diminuição do volume o preço sobe e no final de 2006 pra cá o custo sempre subiu acima da inflação. Era um real em 2006 e hoje $\mathrm{R} \$ 2.70$, por causa da diminuição da demanda, porque boa parte da população deixou de andar de ônibus.

O sistema funciona bem na modalidade do Ligeirão Expresso, porque ele pega a canaleta, e os outros todos são problemáticos no horário de pico. Do centro até o ponto final leva em torno de 40 minutos pelo sistema expresso em média percorre $20 \mathrm{~km}$. Mas com a integração pode levar uma hora e meia. Então as pessoas desistiram do ônibus por levar uma hora e meia para integrar, e isso expulsa as pessoas que saem do sistema. Por isso o sujeito prefere uma moto que cresceu exponencialmente a demanda. E o ônibus não é uma opção dependendo onde vai. Claro se for de ponto a ponto ele é eficiente, mas quando precisa fazer essas integrações, então cai a eficiência e leva ao transporte individual.

Se pensar na integração mais do centro urbano, mais perto do setor público num raio de $3 \mathrm{~km}$ do centro para o interior, você tem uma eficiência urbanísticas exemplar, limpeza, asfalto, etc. Mas digamos que há uma eficiência de serviços e logísticas digamos nesse raio de $3 \mathrm{~km}$. Na medida que se afasta dessa distância começa a ocorrer problemas. Curitiba fez alguma reforma em função do belo, criou-se paisagens belas e lugares turísticos, criando a capital ecológica do país.

Criou-se o que se diz "o mito da cidade modelo", que vendeu a qualidade no centro, mas se mascarou a periferia. Então podemos dizer que temos uma cidade fictícia e outra cidade real. Foi feito um levantamento que não se achou nenhum postal, nada que desqualificasse Curitiba, nas bancas de jornais onde são vendidos esses cartões postais. Os postais foram tirados nos dias 
CROCETI, Z. Urbanização e mobilidade em Curitiba: gênese, ...

limpos, com sol, sem nenhuma fumaça, não existe poluição, nunca chove, sempre sol. Quem puder ir a Curitiba venha que é uma "maravilha", tudo funciona, é o paraíso na Terra.

Então a ideia desta cidade vai sendo desmascarada aos poucos. Foi escondida as favelas. Mas outros órgãos começaram a mapear e alguém apresentou o mapa de 430 favelas em Curitiba e o prefeito quase morreu. Porque daí começou o debate da cidade real $\mathrm{x}$ cidade fictícia. Tinha aquela coisa da eficiência, o que na canaleta é mesmo, porque não leva mais de um minuto de espera entre os ônibus no horário de pico. Se não quer pegar esse que está cheio, espera um minuto que vem outro mais vazio. Mas se sair dessa canaleta, você está com problema, porque tem bairro que você espera uma hora. Tem bairro que tem um ou dois veículos operando. Quer dizer, as vilas mais afastadas com uma demanda menor de passageiros.

Para finalizar, Curitiba é uma maravilha, cinematográfica na região central. Vários Parques; Tanguá, Tingui, Barigui, São Lourenço, Barreirinha, Bacacheri, portais comemorativos das migrações, do Japão, da Itália, da Ucrânia, Polonesa, etc. Vários jardins, como o botânico, que era a mais antiga favela da cidade.

Mas temos também dezenas de favelas, a mais antiga era a Vila Pinto, berço do Samba de Curitiba, hoje Vila Torres. Lá e em muitos outros lugares tivemos o povo na rua, pedindo o fim do planejamento excludente, não querem mais esse planejamento. Outra referência diz que é a gestão do lixo, com os carrinhos ecológicos, que facilitam o deslocamento, o pessoal não puxa peso, como cidade de primeiro mundo.

\section{Considerações finais}

Aceitamos a formulação que a Cidade é uma criação da humanidade. Ela é responsável pela passagem do estágio do pensamento mítico ao filosófico, esse um produto da vida em sociedade. Dessa maneira as relações e inter-relações dentro do sítio urbano não foram pensadas previamente e nem planejadas, suas articulações urbanísticas surgiram espontaneamente, só se 
CROCETI, Z. Urbanização e mobilidade em Curitiba: gênese, ...

tornaram problemas no século XVIII, com a democratização e com a ampliação da cidadania.

Na maior parte as cidades são naturais ou espontâneas, sem um planejamento prévio, sem uma organização ideológica e excludente, a necessidade de resolver o "caos" urbano é recente, tem início no século XIX, e se consolida no pós II Guerra, é lá pelos anos 1950 que surgem a necessidade de planejamento urbano mais sistemático e a obrigatoriedade do plano diretor, que no caso do Brasil ainda não se efetivou em sua totalidade.

Por que será que as cidades atraem tantas pessoas? As cidades antes como hoje funcionam como verdadeiras bombas de sucção do sistema capitalista, devido à sedução que elas impõem através de sua infraestrutura e sua diversidade de serviços. Quanto maior e mais complexa ela for, maior será seu fetiche e poder de atração. Claro que algumas pessoas são atraídas pelas vantagens do anonimato que um grande centro proporciona, alguns para desenvolver certos tipos de negócios que serão possíveis da grande metrópole, outras a procuram para aplicar certos tipos de golpes, crime organizado (Comando Vermelho, PCC, etc.), outros a procuram para arrumar emprego, melhorar de vida, são os pobres e excluídos por exemplo, portanto são muitos os interesses que atraem as pessoas para grandes cidades.

Questão do êxodo, é rural ou urbano? A questão da circulação das pessoas e seus deslocamentos no século XXI estão cada vez mais complexos, qualquer resposta curta será reducionista, mas vamos lá... Hoje as migrações da população são de uma complexidade sem precedentes na história da sociedade humana. Podemos afirmar que existem migrações e deslocamentos do campo para cidade ainda, como no caso do município de São Paulo, por exemplo, ocorre êxodo urbano devido à violência crescente e degradação da qualidade de vida, mas a saída dos grandes centros são feitos pela Elite e classe média, que detém um conhecimento e poder econômico que garantem o direito de escolha, mas no caso dos pobres, os excluídos, a cidade continua sendo um lugar da sedução, pois na posição que eles se encontram, 
CROCETI, Z. Urbanização e mobilidade em Curitiba: gênese, ...

a violência não os atinge, eles não são consumidores, eles são sim os que causam medo nas Elites e na classe média abastada, essa é uma contradição social muito grave, isso é, os que não usufruem da cidade, ou seja, aqueles que não têm direito a Cidade, são justamente os que preferem as cidades, é a contradição da sobrevivência.

Como os problemas poderiam ser resolvidos a curto, médio e longo prazo? Como já explicamos, o que é problema para uma categoria social, pode não ser para outra, e vice e versa, mas os problemas urbanos dos grandes centros são hoje, a fluidez do trânsito e violência para uma parte da população e falta de infraestrutura e presença do Estado para outra parte da sociedade, e muitos dos problemas urbanos são causados pela ausência do Estado, preenchida pelo crime organizado que monta um Estado paralelo. Para tanto em curto prazo seria maior presença do Estado em áreas de risco social, investimento na infraestrutura no médio prazo e uma política em longo prazo de distribuição de renda.

A questão da circulação das pessoas e seus deslocamentos no século XXI estão cada vez mais complexos, qualquer resposta curta será reducionista, mas vamos lá... Hoje as migrações da população são de uma complexidade sem precedentes na história da sociedade humana. Podemos afirmar que existem migrações e deslocamentos do campo para cidade ainda, como no caso do município de São Paulo, por exemplo, ocorre êxodo urbano devido à violência crescente e degradação da qualidade de vida, mas a saída dos grandes centros são feitos pela Elite e classe média, que detém um conhecimento e poder econômico que garantem o direito de escolha, mas no caso dos pobres, os excluídos, a cidade continua sendo um lugar da sedução, pois na posição que eles se encontram, a violência não os atinge, eles não são consumidores, eles são sim os que causam medo nas Elites e na classe média abastada, essa é uma contradição social muito grave, isso é, os que não usufruem da cidade, ou seja, aqueles que não têm direito a 
CROCETI, Z. Urbanização e mobilidade em Curitiba: gênese, ...

Cidade, são justamente os que preferem as cidades, é a contradição da sobrevivência (SANTOS, p. 58-63: 1989).

Se entendemos que mobilidade urbana é a capacidade de organização e racionalização, que permitem criar condições adequadas de movimentação das populações das cidades. O importante para a eficiência da mobilidade urbana seria a existência de um único comando, do contrário, dificilmente haverá unidade no planejamento e operação sem unidade, haverá desperdício de recursos públicos nos investimentos, encarecimento dos custos operacionais e um enorme prejuízo aos usuários, que terão de pagar duas passagens para atingir o seu destino.

Sair desse modelo único de transporte urbano, e investir na multimodalidade, integração ônibus, automóveis, bicicletas, metrô, trens de superfície. É poder chegar no terminal, estacionar o carro e vir de ônibus para o centro. Financiamento solidário da mobilidade. Temos que debater e encarar a mobilidade como um direito e não como serviço pago. Vários lugares do mundo resolveram o problema da mobilidade a partir dessa ideia. Que é uma questão estratégica, o transporte subsidiado 100\%, mas não como bandeira política, mas como uma solução que o transporte interurbano e metropolitano traz, sistema mais economia e eficiente para a infraestrutura da cidade.

As aglomerações, em suas diferentes escalas, são a marca da morfologia da rede urbana da RMC. Em torno delas, giram as questões centrais relativas às transformações sócio espaciais dessa Região. Portanto, prioridades e recomendações devem estar voltadas para administrar e maximizar as vantagens comparativas e, ao mesmo tempo, superar suas contradições. 
CROCETI, Z. Urbanização e mobilidade em Curitiba: gênese, ,...

\section{Referências bibliográficas}

CAMPOS, R. F. Analise da Influência da Orientação da Testada dos Lotes da Ocupação do Setor Estrutural de Curitiba. Dissertação de mestrado no Programa de Pós-Graduação em Construção Civil. Universidade Federal do Paraná, 2005.

GARCIA F. E. S. Cidade espetáculo: politica, planejamento e City marketing. Curitiba: Palavra, 1997.

IPPUC. Legislação e uso do solo. Curitiba, 1979.

Análise, diagnóstico e diretrizes do Plano Municipal de $\overline{\text { Desenvolvimento. Curitiba, } 2001 .}$

KLEINKE, M. de L. U. e MOURA, Rosa. R. paran. Desenv., Curitiba, n.95, jan./abr. 1999, p. 3-25. Espacialidades de Concentração na Rede Urbana da Região Sul. Curitiba: IPARDES.

KUCHPIL E. Cidade Vertical - morfologia, densidade e qualidade de vida urbana. Curitiba, 2002. Dissertação de Mestrado. PUC-PR.

LOBO, M. L. C; SCHEER. S; CAMPOS, F. Sub-centro do Portão: estudo de caso com computação gráfica. Curitiba: UFPR, 1988. Relatório de pesquisa.

MENEZES C L Desencolhimento urbano e meio ambiente: a experiência de Curitiba. Campinas: Papirus, 1996.

OLIVEIRA, D de. Curitiba e o mito da cidade modelo. Curitiba: UFPR, 2000. 
CROCETI, Z. Urbanização e mobilidade em Curitiba: gênese, ...

OLIVEIRA, M. de. A trajetória do discurso ambiental em Curitiba (1960-2000). In: Revista de Sociologia e Política, Curitiba, nº16, p. 97-106, 2001.

PEREIRA, G. de E. Planejamento urbano e qualidade de vida reflexão a partir de um bairro de Curitiba. Rio de Janeiro 1993. Dissertação (Mestrado em Planejamento Urbano e Regional) Instituto de Pesquisa e planejamento Urbano e Regional. Universidade Federal do Rio de Janeiro.

PMC - PREFEITURA MUNICIPAL DE CURITIBA. Lei $\mathbf{n}^{\mathbf{0}}$ 2.828, de 31 de junho de 1966 Institui o Plano Diretor de Curitiba e aprova as suas Diretrizes Básicas, para orientação e controle do desenvolvimento integrado do município. Diário Oficial do Município. Curitiba, 1966.

RABINOVITCH, J. Innovative land use and public transport policy - the case of Curitiba, Brazil. In: Land Use Policy, Elsevier v.13, p. 51-67, 1996.

SANTORO, R. D. V. del. Curitiba: um modelo em evolução. Curitiba: Foco Editorial, 2002.

Santos, M. O Espaço do Cidadão. São Paulo: Nobel, 1989.

Técnica, espaço, tempo: globalização e meio técnicocientífico-informacional. São Paulo: Hucitec, 1994.

SERETE, Plano Preliminar de Urbanismo. Curitiba, 1965.

SOUZA, N. R. de Planejamento urbano, saber e poder - o governo do espaço e da população em Curitiba. São Paulo, 1999.315 f Tese. Universidade de São Paulo. 
CROCETI, Z. Urbanização e mobilidade em Curitiba: gênese, ...

TREMARIN A. R. Análise do processo de ocupação e verticalização dos setores estruturais Norte e Sul de Curitiba. Curitiba, 2001. Dissertação. Universidade Federal do Paraná.

XAMER, A Arquitetura moderna em Curitiba. São Paulo: PDL 1985.

Recebido em

Aceito em 